Published in final edited form as:

Semin Oncol Nurs. 2013 November ; 29(4): . doi:10.1016/j.soncn.2013.08.008.

\title{
Neuroimaging, Cancer, and Cognition: State of the Knowledge
}

\author{
Kelly N. Holohan, BS [graduate student], \\ Indiana University School of Medicine, Indianapolis, IN \\ Diane Von Ah, PhD, RN [Assistant Professor], \\ Department of Adult Health, Indiana University School of Nursing, Indianapolis, IN
}

Brenna C. McDonald, PsyD, MBA [Assistant Professor], and

Indiana University School of Medicine, Indianapolis, IN

Andrew J. Saykin, PsyD* [Professor and Director]

Center for Neuroimaging, Indiana University School of Medicine, Indianapolis, IN

\section{Abstract}

Objectives-To review neuroimaging research concerning cancer- and treatment-related changes in brain structure and function, clinical perspectives, and future directions.

Data Sources-Peer-reviewed literature

Conclusion-Cancer and chemotherapy are associated with cerebral structural and functional alterations in breast cancer patients which may persist for years; many of these changes are correlated with cognitive complaints or performance. In other cancers there is some evidence that metabolism is altered by cancer, but more research is needed.

Implications for Nursing Practice-Understanding the role of neuroimaging is important to identify the basis of cognitive changes associated with cancer and cancer treatment.

\section{Keywords}

cancer; cognition; neuroimaging; review

\begin{abstract}
Multiple neuroimaging techniques have been applied in studies of cancer- and chemotherapy treatment-related cognitive dysfunction, with promising results. Magnetic resonance imaging (MRI) most commonly is employed. MRI uses radio frequencies to manipulate magnetization of various types of nuclei in the body, with the resulting signatures used to produce detailed 2- or 3-dimensional images. ${ }^{1,2}$ This technology has been adapted to measure a number of different factors, including brain gray matter (GM), white matter (WM), and neural activity using functional MRI (fMRI). WM structure and directional diffusion, or 'fractional anisotropy' (FA), is measured through diffusion tensor imaging (DTI) of magnetized cerebral water flow. ${ }^{3,4}$ Brain activation is obtained using magnetized hemoglobin to observe oxygenated blood flow; increased blood flow to active areas is
\end{abstract}

(C) 2013 Elsevier Inc. All rights reserved.

"Corresponding author: Andrew J. Saykin, Center for Neuroimaging, Department of Radiology and Imaging Sciences, Indiana University School of Medicine, 355 West $16^{\text {th }}$ Street, GH Suite 4100, Indianapolis, IN 46202, USA asaykin@iupui.edu; Phone: 317-963-7501.

Publisher's Disclaimer: This is a PDF file of an unedited manuscript that has been accepted for publication. As a service to our customers we are providing this early version of the manuscript. The manuscript will undergo copyediting, typesetting, and review of the resulting proof before it is published in its final citable form. Please note that during the production process errors may be discovered which could affect the content, and all legal disclaimers that apply to the journal pertain. 
measured during tasks, and fMRI has been reliably correlated with neural activity ${ }^{5-7}$ Proton MR spectroscopy (1H-MRS) also uses magnetic resonance technology to measure levels of brain metabolites and neurochemical changes. ${ }^{8}$ MRI techniques have the advantage of being non-invasive and do not require ionizing radiation, permitting multiple measurements and longitudinal studies. Positron emission tomography (PET) is another technique that has been employed to measure brain activity and metabolism using an injected radioactive tracer coupled to a bioactive molecule; two common tracers which will be discussed are [O-15], which measures blood flow, and [F-18] Fluorodeoxyglucose (FDG), which measures metabolism. ${ }^{9-11}$ These techniques can be used to investigate neurophysiological changes and may help explain the mechanisms of cognitive dysfunction in cancer patients.

The purpose of this research brief is to review the current literature on neuroimaging studies of cancer and chemotherapy-induced cerebral alterations, and to provide perspective on the state of research and future directions. Our primary goal is to review and synthesize the evidence regarding the impact of non-central nervous system cancer and related treatment on brain structure and function. Treatments administered for cancers in the central nervous system (CNS) and lymphatic systems operate under different parameters and goals and are beyond the scope of this review. ${ }^{12}$ Findings from imaging studies have the potential to identify causal mechanisms and possible therapeutic directions for cancer and treatmentrelated cognitive dysfunction.

\section{Overview of Findings}

We reviewed 35 neuroimaging studies. The overwhelming majority of the work in this area has been focused on breast cancer (BC) patients, with $27 \mathrm{BC}$ studies ${ }^{13-40}$ and only eight studies in other cancers. ${ }^{41-48}$ In the BC studies, we noted that 18 studies were focused on survivors, ${ }^{14-17,19-21,23-30,38-40}$ three were pre-treatment cancer studies, ${ }^{18,36,37}$ and six were longitudinal studies in which women were followed pre- and post-treatment. ${ }^{13,22,31-34}$ These studies are grouped by methodology and information is provided regarding authors, cohorts, methods, and results in Tables 1-3. The majority of non-BC studies (see Table 4) were focused on the association of metabolism with psychological factors or cancer. In summary, research to date has been focused on the cognitive effects of $\mathrm{BC}$ treatment, likely due to the large pool of survivors with cognitive concerns. ${ }^{35,40,49,50}$ This brief provides an overview including all types of neuroimaging studies on multiple types of cancer.

\section{Breast Cancer Survivor Studies}

Neuroimaging studies began with a focus on survivors treated with chemotherapy. Initial findings on this topic presented in 2003 indicated that chemotherapy treatment was associated with structural changes in gray matter (GM), white matter (WM) loss, and abnormal regional cerebral metabolism measured by PET. ${ }^{40,51,52}$ The focus of these BC studies (Table 1) was on patients treated with chemotherapy (C+). All studies included a C+ category, and 15 included healthy controls (HC). ${ }^{14-17,19,23-30,38,40}$ However, only seven studies included untreated survivors $(\mathrm{C}-$ ), so the findings are limited since in most studies differentiation between changes caused by treatment or cancer was not possible. ${ }^{20,21,23,26,28,38,39}$

The major endpoints of these studies were cerebral structural and activation changes. GM and WM damage consistently were reported in survivors except for Yoshikawa et al. This discrepancy may be explained by unique cohort characteristics such as ethnicity, since the majority of studies were conducted with Caucasian patients and this study only included Japanese individuals. ${ }^{39}$ Authors of three studies reported association of these changes with increased cognitive complaints or decreased neuropsychological test performance. ${ }^{16,19,23}$ Results from all six functional studies demonstrated activation or metabolic changes in 
survivors. ${ }^{19,21,24,27,28,38}$ The direction of activation change seems to be task-dependent. In two studies activation change was found to be correlated with increased cognitive complaints. ${ }^{19,28}$ Importantly, in two studies de Ruiter et al. found treatment-related cognitive alterations almost a decade after treatment, accompanied by lower neuropsychological test performance and increased cognitive complaints. ${ }^{20,21}$ Koppelmans et al. conducted two studies with a very large survivor cohort over 20 years post-treatment. Findings included decreased brain volume, GM, and decreased WM integrity with increasing time since treatment, supporting the idea that $\mathrm{BC}$, treatment, or both are responsible for long-term possibly deleterious cognitive changes. ${ }^{29,30}$ Results from all but one of these studies support the association of chemotherapy treatment with some measure of cognitive structural or function alteration which could lead to cognitive dysfunction. The majority of these findings are accompanied by neuropsychological testing deficits, increased self-reported cognitive complaints, or both, indicating the functional relevance of these measures. However, more work is needed to discern which measures are specific to treatment and which to cancer.

\section{Pre-Chemotherapy Breast Cancer Studies}

Prompted by the need to discriminate between effects of $\mathrm{BC}$ and treatment, three imaging studies were designed specifically to examine the influence of $\mathrm{BC}$ on cognition. ${ }^{18,36,37} \mathrm{BC}$ patients were examined before treatment and compared to HC with fMRI during neuropsychological tasks. Activation decrease was observed for patients during response inhibition and working memory tasks, while activation increase was observed during a visuospatial task. Interestingly, two studies by Scherling et al. were performed in the same cohort using different tasks and found evidence that activation increase or decrease may be dependent on the type of task. These activation changes were not associated with test performance changes, suggesting that they may be compensatory. ${ }^{36,37}$ This lack of association suggests that while $\mathrm{BC}$ does appear to influence cognitive activation, the effects may vary depending on the cognitive process being assessed. Activation also may be a more sensitive measure of change than test performance.

\section{Longitudinal Breast Cancer Treatment Studies}

The existing longitudinal studies particularly are helpful in differentiating cancer and chemotherapy effects, especially as four of the six studies reviewed included C- and HC. ${ }^{22,31-34}$ Pre-treatment measures for all patients also allow discrimination of cancer and chemotherapy effects over time. Results of all six studies demonstrated some cerebral changes in cancer patients compared to controls, and results of the five studies with Ccontrols indicated that some of these changes are specifically attributable to chemotherapy, while others appear to occur in cancer patients regardless of treatment. These findings suggest that while cancer patients experience cognitive alterations, chemotherapy may have independent effects. Thus $\mathrm{C}+$ patients may experience increased alterations compared to $\mathrm{C}-$ patients, and may be at increased risk for cognitive sequelae. Two studies were designed to investigate effects of cancer and chemotherapy more than four months post-treatment with $\mathrm{C}$ ,$+ \mathrm{C}-$, and $\mathrm{HC}$ groups. Findings included independent cancer and treatment-related activation and GM changes post-treatment. ${ }^{33,34}$ At one year post-treatment, some activation changes still were observed in $\mathrm{C}+$ and $\mathrm{C}-$, and $\mathrm{GM}$ decrease was not fully recovered in $\mathrm{C}+$ patients, indicating that structural and functional changes can persist for significant periods of time.

\section{Non-BC Studies}

As stated previously, there is a dearth of research on this topic in non-BC cancers. Additionally, of the eight studies found, three studies were focused on the correlation of 
metabolism with psychological factors instead of cognitive factors. ${ }^{41-48}$ However, these studies are still informative given that depression and cognitive complaints previously have been linked. ${ }^{53}$ These findings provide indirect evidence for association of brain metabolism with cognitive complaints. Interestingly, results of a study in a lung cancer cohort indicated that patients had increased metabolism pre-treatment, suggesting that cancer may have a transitory metabolic effect on the brain in lung cancer. ${ }^{47}$ Results from another study of lung cancer indicated that patients had altered neurochemistry pre-treatment, further supporting the hypothesis that lung cancer may alter cerebral activity. ${ }^{48}$

Six studies were conducted in a mixed cancer population. All were limited by the assumption that the cancer types included in the studies affect the brain in a similar manner, which may not be true. ${ }^{41-46}$ Only one study was designed to investigate the effect of chemotherapy treatment on metabolism. Decreased metabolism in C+ patients was found, demonstrating that other cancer populations do experience treatment changes. ${ }^{45}$ Three studies in mixed cohorts of treated and untreated cancer patients found decreased metabolism associated with cancer, supporting the possibility of cancer-induced cerebral alterations in non-BC patients. ${ }^{44-46}$ However, in seven of the eight studies only FDG-PET imaging was used. Clearly, more research is needed to investigate other imaging types in these populations. Future work also should include longitudinal studies with $\mathrm{C}+, \mathrm{C}-$, and $\mathrm{HC}$ groups to identify cancer and chemotherapy-specific changes, and should control for cancer type, or focus on one cancer.

\section{Clinical Implications and Future Research}

Oncology nurses and other healthcare providers should understand the role neuroimaging can play in identifying cognitive changes associated with cancer and cancer treatment, as well as the impact of these changes on social relationships, everyday functioning and work ability. ${ }^{54}$ Directions for future neuroimaging research are: (1) to elucidate cancer and treatment-related changes in more diverse cohorts; (2) to utilize a range of imaging methodologies, as most studies to date have been focused solely on MRI and fMRI; and (3) to utilize neuroimaging in interventional cognitive research to establish efficacy as well as elucidate therapeutic mechanisms of action.

\section{Conclusion}

Results from neuroimaging studies in BC cohorts have provided solid evidence supporting a variety of cerebral structural and functional alterations associated with cancer and chemotherapy treatment. Evidence from BC survivors suggests that some of these changes persist for years. Little imaging research has been conducted in other cancer types; however, preliminary studies support cancer-related cerebral metabolic changes. More research is needed to clarify the individual roles of cancer and treatment-related changes, especially in non-BC populations.

\section{Acknowledgments}

From Indiana University-Purdue University Indianapolis

Supported in part by the National Institutes of Health, including National Cancer Institute (R25 CA117865, R01 CA101318, P30 CA082709), National Center for Research Resources (U54 RR025761, C06 RR020128, S10 RR027710), National Institute on Aging (R01 AG019771, P30 AG010133), and a Robert Wood Johnson Foundation Nurse Faculty Scholar Award (\#64194). 


\section{References}

1. Silk TJ, Wood AG. Lessons about neurodevelopment from anatomical magnetic resonance imaging. J Dev Behav Pediatr. 2011; 32(2):158-168. [PubMed: 21200332]

2. Ashburner J, Friston KJ. Voxel-based morphometry--the methods. NeuroImage. 2000; 11(6 Pt 1): 805-821. [PubMed: 10860804]

3. Assaf Y, Pasternak O. Diffusion tensor imaging (DTI)-based white matter mapping in brain research: a review. J Mol Neurosci. 2008; 34(1):51-61. [PubMed: 18157658]

4. Basser PJ, Mattiello J, LeBihan D. MR diffusion tensor spectroscopy and imaging. Biophys J. 1994; 66(1):259-267. [PubMed: 8130344]

5. Lee MH, Smyser CD, Shimony JS. Resting-State fMRI: A Review of Methods and Clinical Applications. AJNR Am J Neuroradiol. 2012 Epub ahead of print.

6. Huettel, SASA.; McCarthy, G. Functional Magnetic Resonance Imaging. 2 ed.. Sinauer Associates; Sunderland, MA: 2009.

7. Christen T, Bolar DS, Zaharchuk G. Imaging Brain Oxygenation with MRI Using Blood Oxygenation Approaches: Methods, Validation, and Clinical Applications. AJNR Am J Neuroradiol. 2012 Epub ahead of print.

8. Posse S, Otazo R, Dager SR, Alger J. MR spectroscopic imaging: Principles and recent advances. J Magn Reson Imaging. 2013; 37(6):1301-25. [PubMed: 23188775]

9. Pike VW. PET radiotracers: crossing the blood-brain barrier and surviving metabolism. Trends Pharmacol Sci. 2009; 30(8):431-440. [PubMed: 19616318]

10. Silverman DH, Alavi A. PET imaging in the assessment of normal and impaired cognitive function. Radiol Clin North Am. 2005; 43(1):67-77, x. [PubMed: 15693648]

11. Silverman DH, Mosconi L, Ercoli L, Chen W, Small GW. Positron emission tomography scans obtained for the evaluation of cognitive dysfunction. Semin Nucl Med. 2008; 38(4):251-261. [PubMed: 18514081]

12. Butler RW, Haser JK. Neurocognitive effects of treatment for childhood cancer. Ment Retard Dev Disabil Res Rev. 2006; 12(3):184-191. [PubMed: 17061287]

13. Ganz PA, Bower JE, Kwan L, et al. Does tumor necrosis factor-alpha (TNF-alpha) play a role in post-chemotherapy cerebral dysfunction? Brain Behav Immun. 2013; 30(Supplement):S99-108. [PubMed: 22884417]

14. Kesler S, Janelsins M, Koovakkattu D, et al. Reduced hippocampal volume and verbal memory performance associated with interleukin- 6 and tumor necrosis factor-alpha levels in chemotherapytreated breast cancer survivors. Brain Behav Immun. 2013; 30(Supplement):S109-16. [PubMed: 22698992]

15. Abraham J, Haut MW, Moran MT, Filburn S, Lemiuex S, Kuwabara H. Adjuvant chemotherapy for breast cancer: effects on cerebral white matter seen in diffusion tensor imaging. Clin Breast Cancer. 2008; 8(1):88-91. [PubMed: 18501063]

16. Bergouignan L, Lefranc JP, Chupin M, Morel N, Spano JP, Fossati P. Breast cancer affects both the hippocampus volume and the episodic autobiographical memory retrieval. PLoS One. 2011; 6(10):e25349. [PubMed: 22016764]

17. Bruno J, Hosseini SM, Kesler S. Altered resting state functional brain network topology in chemotherapy-treated breast cancer survivors. Neurobiol Dis. 2012; 48(3):329-338. [PubMed: 22820143]

18. Cimprich B, Reuter-Lorenz P, Nelson J, et al. Prechemotherapy alterations in brain function in women with breast cancer. J Clin Exp Neuropsychol. 2010; 32(3):324-331. [PubMed: 19642048]

19. Conroy SK, McDonald BC, Smith DJ, et al. Alterations in brain structure and function in breast cancer survivors: effect of post-chemotherapy interval and relation to oxidative DNA damage. Breast Cancer Res Treat. 2013; 137(2):493-502. [PubMed: 23263697]

20. de Ruiter MB, Reneman L, Boogerd W, et al. Late effects of high-dose adjuvant chemotherapy on white and gray matter in breast cancer survivors: converging results from multimodal magnetic resonance imaging. Hum Brain Mapp. 2012; 33(12):2971-2983. [PubMed: 22095746] 
21. de Ruiter MB, Reneman L, Boogerd W, et al. Cerebral hyporesponsiveness and cognitive impairment 10 years after chemotherapy for breast cancer. Hum Brain Mapp. 2011; 32(8):12061219. [PubMed: 20669165]

22. Deprez S, Amant F, Smeets A, et al. Longitudinal assessment of chemotherapy-induced structural changes in cerebral white matter and its correlation with impaired cognitive functioning. J Clin Oncol. 2012; 30(3):274-281. 20. [PubMed: 22184379]

23. Deprez S, Amant F, Yigit R, et al. Chemotherapy-induced structural changes in cerebral white matter and its correlation with impaired cognitive functioning in breast cancer patients. Hum Brain Mapp. 2011; 32(3):480-493. [PubMed: 20725909]

24. Ferguson RJ, McDonald BC, Saykin AJ, Ahles TA. Brain structure and function differences in monozygotic twins: possible effects of breast cancer chemotherapy. Hum Brain Mapp. 2011; 32(3):480-493. [PubMed: 20725909]

25. Hosseini SM, Koovakkattu D, Kesler SR. Altered small-world properties of gray matter networks in breast cancer. BMC Neurol. 2012; 12:28. [PubMed: 22632066]

26. Inagaki M, Yoshikawa E, Matsuoka Y, et al. Smaller regional volumes of brain gray and white matter demonstrated in breast cancer survivors exposed to adjuvant chemotherapy. Cancer. 2007; 109(1):146-156. [PubMed: 17131349]

27. Kesler SR, Bennett FC, Mahaffey ML, Spiegel D. Regional brain activation during verbal declarative memory in metastatic breast cancer. Clin Cancer Res. 2009; 15(21):6665-6673. [PubMed: 19843664]

28. Kesler SR, Kent JS, O'Hara R. Prefrontal cortex and executive function impairments in primary breast cancer. Arch Neurol. 2011; 68(11):1447-1453. [PubMed: 22084128]

29. Koppelmans V, de Ruiter MB, van der Lijn F, et al. Global and focal brain volume in long-term breast cancer survivors exposed to adjuvant chemotherapy. Breast Cancer Res Treat. 2012; 132(3): 1099-1106. [PubMed: 22205140]

30. Koppelmans V, Groot MD, de Ruiter MB, et al. Global and focal white matter integrity in breast cancer survivors 20 years after adjuvant chemotherapy. Hum Brain Mapp. 2012 Epub ahead of print.

31. Lopez Zunini RA, Scherling C, Wallis N, et al. Differences in verbal memory retrieval in breast cancer chemotherapy patients compared to healthy controls: a prospective fMRI study. Brain Imaging Behav. 2012 Epub ahead of print.

32. McDonald BC, Conroy SK, Ahles TA, West JD, Saykin AJ. Gray matter reduction associated with systemic chemotherapy for breast cancer: a prospective MRI study. Breast Cancer Res Treat. 2010; 123(3):819-828. [PubMed: 20690040]

33. McDonald BC, Conroy SK, Ahles TA, West JD, Saykin AJ. Alterations in brain activation during working memory processing associated with breast cancer and treatment: a prospective functional magnetic resonance imaging study. J Clin Oncol. 2012; 30(20):2500-2508. [PubMed: 22665542]

34. McDonald BC, Conroy SK, Smith DJ, West JD, Saykin AJ. Frontal gray matter reduction after breast cancer chemotherapy and association with executive symptoms: A replication and extension study. Brain Behav Immun. 2013; 30(Supplement):S117-S125. [PubMed: 22613170]

35. Reuter-Lorenz PA, Cimprich B. Cognitive function and breast cancer: promise and potential insights from functional brain imaging. Breast Cancer Res Treat. 2013; 137(1):33-43. [PubMed: 23053652]

36. Scherling C, Collins B, Mackenzie J, Bielajew C, Smith A. Pre-chemotherapy differences in visuospatial working memory in breast cancer patients compared to controls: an FMRI study. Front Hum Neurosci. 2011; 5:122. [PubMed: 22053153]

37. Scherling C, Collins B, Mackenzie J, Bielajew C, Smith A. Prechemotherapy differences in response inhibition in breast cancer patients compared to controls: a functional magnetic resonance imaging study. J Clin Exp Neuropsychol. 2012; 34(5):543-560. [PubMed: 22380580]

38. Silverman DH, Dy CJ, Castellon SA, et al. Altered frontocortical, cerebellar, and basal ganglia activity in adjuvant-treated breast cancer survivors 5-10 years after chemotherapy. Breast Cancer Res Treat. 2007; 103(3):303-311. [PubMed: 17009108] 
39. Yoshikawa E, Matsuoka Y, Inagaki M, et al. No adverse effects of adjuvant chemotherapy on hippocampal volume in Japanese breast cancer survivors. Breast Cancer Res Treat. 2005; 92(1): 81-84. [PubMed: 15980995]

40. Saykin AJ, Ahles TA, McDonald BC. Mechanisms of chemotherapy-induced cognitive disorders: neuropsychological, pathophysiological, and neuroimaging perspectives. Semin Clin Neuropsychiatry. 2003; 8(4):201-216. [PubMed: 14613048]

41. Kumano H, Ida I, Oshima A, et al. Brain metabolic changes associated with predispotion to onset of major depressive disorder and adjustment disorder in cancer patients--a preliminary PET study. J Psychiatr Res. 2007; 41(7):591-599. [PubMed: 16684544]

42. Tashiro M, Itoh M, Kubota K, et al. Relationship between trait anxiety, brain activity and natural killer cell activity in cancer patients: a preliminary PET study. Psychooncology. 2001; 10(6):541546. [PubMed: 11747066]

43. Tashiro M, Juengling FD, Moser E, et al. High social desirability and prefrontal cortical activity in cancer patients: a preliminary study. Med Sci Monit. 2003; 9(4):CR119-124. [PubMed: 12709669]

44. Tashiro M, Juengling FD, Reinhardt MJ, et al. Reproducibility of PET brain mapping of cancer patients. Psychooncology. 2000; 9(2):157-163. [PubMed: 10767753]

45. Tashiro M, Juengling FD, Reinhardt MJ, et al. Depressive state and regional cerebral activity in cancer patients - a preliminary study. Med Sci Monit. 2001; 7(4):687-695. [PubMed: 11433196]

46. Tashiro M, Kubota K, Itoh M, et al. Hypometabolism in the limbic system of cancer patients observed by positron emission tomography. Psychooncology. 1999; 8(4):283-286. [PubMed: 10474846]

47. Golan H, Kennedy JA, Frenkel A, et al. Brain mapping of patients with lung cancer and controls: inquiry into tumor-to-brain communication. J Nucl Med. 2009; 50(7):1072-1075. [PubMed: 19525465]

48. Benveniste H, Zhang S, Reinsel RA, et al. Brain metabolomic profiles of lung cancer patients prior to treatment characterized by proton magnetic resonance spectroscopy. Int J Clin Exp Med. 2012; 5(2):154-164. [PubMed: 22567176]

49. Deprez S, Billiet T, Sunaert S, Leemans A. Diffusion tensor MRI of chemotherapy-induced cognitive impairment in non-CNS cancer patients: a review. Brain Imaging Behav. 2013 Epub ahead of print.

50. McDonald BC, Saykin AJ. Neurocognitive dimensions of breast cancer and its treatment. Neuropsychopharmacology. 2011; 36(1):355-356. [PubMed: 21116248]

51. Silverman D, Castellon SA, Abraham L, et al. Abnormal regional brain metabolism in breast cancer survivors after adjuvant chemotherapy is associated with cognitive changes. Proc Am Soc Clin Oncol. 2003:22. Abstract 47.

52. Saykin A, Ahles TA, Schoenfeld JD, et al. Gray matter reduction on voxel-based morphometry in chemotherapy-treated cancer survivors. J Int Neuropsychol Soc. 2003; 9(246)

53. Hermelink K, Kuchenhoff H, Untch M, et al. Two different sides of 'chemobrain': determinants and nondeterminants of self-perceived cognitive dysfunction in a prospective, randomized, multicenter study. Psychooncology. 2010; 19(12):1321-1328. [PubMed: 20127909]

54. Von Ah D, Habermann B, Carpenter JS, Schneider BL. Impact of perceived cognitive impairment in breast cancer survivors. Eur J Oncol Nurs. 2013; 17:236-241. [PubMed: 22901546] 
Table 1

Breast Cancer Survivor Neuroimaging Studies

\begin{tabular}{|c|c|c|c|c|}
\hline Study & Cohort & $\mathbf{P C I}^{a}$ & Method & Results \\
\hline Saykin et al. ${ }^{40}$ & $12 \mathrm{C}^{b}, 12 \mathrm{H}$ & $>5 \mathrm{Y}$ & sMRI & $\mathrm{C}+: \downarrow \mathrm{WM}$ and GM \\
\hline Yoshikawa et al. ${ }^{39}$ & $44 \mathrm{C}+, 31 \mathrm{C}-$ & $>3 \mathrm{Y}$ & sMRI, NP & $\mathrm{C}+$ : No treatment associations \\
\hline Ferguson et al. ${ }^{24}$ & $1 \mathrm{C}+, 1 \mathrm{H}$ & $22 \mathrm{M}$ & s/fMRI, NP, SR & $\mathrm{C}+: \uparrow \mathrm{SR}, \mathrm{WM}$ damage, WMem activation \\
\hline Silverman et al. ${ }^{38}$ & $16 \mathrm{C}+, 5 \mathrm{C}-, 13 \mathrm{H}$ & $5-10 Y$ & $\begin{array}{l}\text { O-15 \& FDG PET, } \\
\text { NP }\end{array}$ & $\begin{array}{l}\mathrm{C}+\text { : altered CBF during memory task; } \\
\text { resting metabolism correlated with task } \\
\text { performance }\end{array}$ \\
\hline Inagaki et al. ${ }^{26}$ & $\begin{array}{c}1 \mathrm{Y}: 51 \mathrm{C}+, 54 \mathrm{C}-, 55 \mathrm{H} ; 3 \mathrm{Y}: 73 \\
\mathrm{C}+, 59 \mathrm{C}-, 37 \mathrm{H}\end{array}$ & $1 \mathrm{Y}$ and $3 \mathrm{Y}$ & sMRI, NP & $\begin{array}{l}1 \mathrm{Y} \mathrm{C}+\text { : } \downarrow \text { GM and WM vs. C-, not vs. H. } \\
3 \mathrm{Y} \mathrm{C+:} \mathrm{no} \mathrm{treatment} \mathrm{association} \mathrm{with} \mathrm{GM/} \\
\text { WM }\end{array}$ \\
\hline Abraham et al. ${ }^{15}$ & $10 \mathrm{C}+, 9 \mathrm{H}$ & $22 \mathrm{M}$ & DTI, NP & $\mathrm{C}+: \downarrow \mathrm{PS}, \mathrm{FA}$ \\
\hline Kesler et al. ${ }^{27}$ & $14 \mathrm{C}+, 14 \mathrm{H}$ & $>6 \mathrm{M}$ & fMRI & $\begin{array}{l}\mathrm{C}+\text { : activation } \downarrow \text { encoding, } \uparrow \text { recall in VDM } \\
\text { task }\end{array}$ \\
\hline Kesler et al. ${ }^{28}$ & $25 \mathrm{C}+, 19 \mathrm{C}-, 18 \mathrm{H}$ & $5 \mathrm{Y}$ & fMRI, NP, SR & $\begin{array}{l}\text { C+ \& C-: } \downarrow \text { activation for EF task } \\
\text { C+: } \uparrow \mathrm{SR} \text { complaints, NP errors, } \downarrow \mathrm{PS}, \downarrow \\
\text { activation correlated with SR, disease } \\
\text { severity }\end{array}$ \\
\hline de Ruiter et al. ${ }^{21}$ & $19 \mathrm{C}+, 15 \mathrm{C}-$ & $>9 \mathrm{Y}$ & fMRI, NP & $\begin{array}{l}\text { HD C+: } \downarrow \text { activation for EF and EMem } \\
\text { tasks, NP }\end{array}$ \\
\hline Deprez et al. ${ }^{23}$ & $17 \mathrm{C}+, 10 \mathrm{C}-, 18 \mathrm{H}$ & $2-4 \mathrm{M}$ & DTI, NP, SR & $\begin{array}{l}\mathrm{C}+: \downarrow \mathrm{FA}, \uparrow \mathrm{MD} \text { vs. } \mathrm{C}-\text { and } \mathrm{H} ; \mathrm{FA} \\
\text { correlated with attention, PS, SR }\end{array}$ \\
\hline Bergouignan et al. ${ }^{16}$ & $16 \mathrm{C}+, 21 \mathrm{H}$ & $18-36 \mathrm{M}$ & sMRI, NP & $\mathrm{C}+: \downarrow \mathrm{GM}, \downarrow \mathrm{NP} ; \mathrm{GM}$ correlated with NP \\
\hline Kesler et al. ${ }^{14}$ & $42 \mathrm{C}+, 35 \mathrm{H}$ & $4.8 \mathrm{Y}$ & sMRI, INF, NP & $\begin{array}{l}\text { C+: } \downarrow \text { GM, NP, } \uparrow \text { INF; } \downarrow \text { GM correlated with } \\
\text { INF }\end{array}$ \\
\hline Koppelmans et al. ${ }^{29}$ & $184 \mathrm{C}+, 368 \mathrm{H}$ & $21 \mathrm{Y}$ & sMRI & $\mathrm{C}+: \downarrow \mathrm{TBV}, \mathrm{GM}$ \\
\hline Koppelmans et al. ${ }^{30}$ & $187 \mathrm{C}+, 374 \mathrm{H}$ & $21 \mathrm{Y}$ & DTI & $\begin{array}{l}\mathrm{C}+\text { : WM integrity correlated with time since } \\
\text { treatment; no change vs. } \mathrm{H}\end{array}$ \\
\hline Hosseini et al. ${ }^{25}$ & $37 \mathrm{C}+, 38 \mathrm{H}$ & $4.5 \mathrm{Y}$ & sMRI & $\begin{array}{l}\text { C+: } \downarrow \text { GM connectivity, organization, } \\
\text { integration }\end{array}$ \\
\hline Bruno et al. ${ }^{17}$ & $34 \mathrm{C}+, 27 \mathrm{H}$ & $5.35 \mathrm{Y}$ & fMRI, SR & $\begin{array}{l}\mathrm{C}+: \uparrow \mathrm{SR}, \downarrow \text { global cluster, nodal degree, } \\
\text { hubs }\end{array}$ \\
\hline de Ruiter et al. ${ }^{20}$ & $17 \mathrm{HD} \mathrm{C}+, 15 \mathrm{C}-$ & $>9 \mathrm{Y}$ & DTI, sMRI, NP, SR & $\begin{array}{l}\mathrm{C}+: \uparrow \mathrm{SR}, \downarrow \mathrm{NP}, \mathrm{GM}, \text { focal FA; } \uparrow \mathrm{MD} \\
\text { correlated with } \downarrow \text { neural markers }\end{array}$ \\
\hline Conroy et al. ${ }^{19}$ & $24 \mathrm{C}+, 23 \mathrm{H}$ & $3-10 Y$ & $\begin{array}{l}\text { s/fMRI, NP, SR, } \\
\text { Comet }\end{array}$ & $\begin{array}{l}\text { C+: } \downarrow \text { GM, WMem activation, NP; GM } \\
\text { correlated with PCI, NP, activation } \\
\text { correlated with PCI, SR, OD }\end{array}$ \\
\hline
\end{tabular}

$\mathrm{PCI}=$ post-chemotherapy interval, $\mathrm{C}+=$ survivors treated with chemotherapy, $\mathrm{C}-=$ =survivors not treated with chemotherapy, $\mathrm{H}=$ healthy controls, $\mathrm{Y}=\mathrm{year}, \mathrm{M}=$ month, $\mathrm{HD}=$ high dose, $\mathrm{sMRI}=$ structural $\mathrm{MRI}$, fMRI=functional MRI, DTI=diffusion tensor imaging, FDG-PET=[F-18] Fluorodeoxyglucose positron emission tomography, Comet=assay of oxidative DNA damage, oxidative DNA damage=OD, $\mathrm{NP}=$ neuropsychological testing, $\mathrm{SR}=$ self-report cognitive complaints assessment, $\downarrow$ decrease, $\hat{=}$ increase, GM=gray matter, WM=white matter, WMem=working memory, $\mathrm{CBF}=$ cerebral blood flow, $\mathrm{PS}=$ processing speed, $\mathrm{FA}=$ fractional anisotropy, $\mathrm{MD}=\mathrm{mean}$ diffusivity, VDM=verbal declarative memory task, $\mathrm{EF}=$ executive function, EMem=episodic memory, TBV=total brain volume

${ }^{a}$ When one number is listed, this is the average length of time post-treatment

$b_{10}$ breast cancer, 2 lymphoma survivors 
Table 2

Pre-Chemotherapy Breast Cancer Neuroimaging Studies

\begin{tabular}{lccl}
\hline Study & Cohort & Method & Results \\
\hline Cimprich et al. ${ }^{18}$ & $10 \mathrm{PC}, 9 \mathrm{H}$ & fMRI & PC: $\downarrow$ speed, accuracy for verbal WMem task, activation \\
Scherling et al. ${ }^{36}$ & $23 \mathrm{PC}, 23 \mathrm{H}$ & fMRI & PC: $\uparrow$ activation during VS task, $\downarrow$ reaction time, errors \\
Scherling et al. ${ }^{37}$ & $23 \mathrm{PC}, 23 \mathrm{H}$ & fMRI & PC: $\downarrow$ activation during RI task, no performance change \\
\hline
\end{tabular}

$\mathrm{PC}=$ cancer patients who have not yet received chemotherapy, $\mathrm{H}=$ healthy controls, fMRI=functional MRI, $\models$ decrease, $\hat{=}$ increase, WMem=working memory, VS=visuospatial, RI=response inhibition 


\section{Table 3}

Longitudinal Breast Cancer Neuroimaging Studies

\begin{tabular}{|c|c|c|c|c|}
\hline Study & Cohort & Measures & Method & Results \\
\hline McDonald et al. ${ }^{32}$ & $17 \mathrm{C}+, 12 \mathrm{C}-, 18 \mathrm{H}$ & $\mathrm{BL}, 1 \mathrm{M}, 1 \mathrm{Y}$ & sMRI & $\begin{array}{l}\mathrm{C}+\& \mathrm{C}-:{ }_{\mathrm{GM}} \text { from } \mathrm{BL} \text { to } 1 \mathrm{M} \\
\mathrm{C}+\text { : some changes persist at } 1 \mathrm{Y}\end{array}$ \\
\hline McDonald et al. ${ }^{33}$ & $16 \mathrm{C}+, 12 \mathrm{C}-, 15 \mathrm{H}$ & $\mathrm{BL}, 1 \mathrm{M}, 1 \mathrm{Y}$ & fMRI & $\begin{array}{l}\mathrm{C}+\& \mathrm{C}-: \uparrow \text { frontal, } \downarrow \text { left parietal } \mathrm{BL} \text { WMem } \\
\text { activation, } 1 \mathrm{M} \downarrow \text { frontal activation, } 1 \mathrm{Y} \text { partial } \\
\text { recovery } \\
\mathrm{C}+: \uparrow \text { frontal activation at } \mathrm{BL}, 1 \mathrm{M}, 1 \mathrm{Y}\end{array}$ \\
\hline McDonald et al. ${ }^{34}$ & $27 \mathrm{C}+, 28 \mathrm{C}-, 24 \mathrm{H}$ & $\mathrm{BL}, 1 \mathrm{M}$ & sMRI, SR & $\mathrm{C}+: \downarrow \mathrm{GM}$ at $1 \mathrm{M} ; \uparrow$ SR correlated with $\downarrow \mathrm{GM}$ \\
\hline Ganz et al. ${ }^{13}$ & $49 \mathrm{C}+, 44 \mathrm{C}-$ & 8.7MD, 14.7MD, 20.7MD & $\begin{array}{l}\text { SR, NP, FDG- } \\
\text { PET, INF }\end{array}$ & $\begin{array}{l}\mathrm{C}+: 8.7 \mathrm{MD} \uparrow \mathrm{SR}, \uparrow \mathrm{INF}, \mathrm{INF} \text { correlated to } \\
\text { inferior frontal metabolism; longitudinal } \downarrow \mathrm{INF} \\
\text { correlated to } \uparrow \mathrm{SR}\end{array}$ \\
\hline Deprez et al. ${ }^{22}$ & $34 \mathrm{C}+, 16 \mathrm{C}-, 19 \mathrm{H}$ & $\mathrm{BL}, 3-4 \mathrm{M}$ & DTI, NP & $\mathrm{C}+: \downarrow \mathrm{NP}$ at $1 \mathrm{M}$ vs. BL; NP correlated with $\downarrow$ FA \\
\hline Lopez Zunini et al. ${ }^{31}$ & $21 \mathrm{C}+, 21 \mathrm{H}$ & $\mathrm{BL}, 1 \mathrm{M}$ & fMRI, NP & $\mathrm{C}+: \downarrow$ VMem activation at $\mathrm{BL}, 1 \mathrm{M}$ vs. $\mathrm{BL}$ \\
\hline
\end{tabular}

$\mathrm{C}+=$ survivors treated with chemotherapy, $\mathrm{C}-=$ survivors not treated with chemotherapy, $\mathrm{H}=$ healthy controls, $\mathrm{BL}=$ baseline (pre-chemotherapy), $\mathrm{M}=$ month post-treatment, $\mathrm{MD}=$ month post-diagnosis, $\mathrm{Y}=$ year post-treatment, sMRI=structural MRI, fMRI=functional MRI, $\mathrm{SR}=$ self-report cognitive assessment, FDG-PET=[F-18] Fluorodeoxyglucose positron emission tomography, INF=inflammatory markers, DTI=diffusion tensor imaging, $\mathrm{NP}=$ neuropsychological testing, $\models$ decrease, $=$ =increase, GM=gray matter, WMem=working memory, FA=fractional anisotropy, VMem=verbal memory 


\section{Table 4}

Non-CNS, Non-Breast Cancer Neuroimaging Studies

\begin{tabular}{|c|c|c|c|c|c|}
\hline Study & Cancer & Cohort & Design & Method & Results \\
\hline Tashiro et al. ${ }^{46}$ & Various & $19 \mathrm{PC}, 17 \mathrm{H}$ & Cross-section & FDG-PET & Cancer: $\downarrow$ metabolism \\
\hline Tashiro et al. ${ }^{44}$ & Various & $1 \mathrm{PC}, 19 \mathrm{C}+/-, 10 \mathrm{H}$ & Cross-section & FDG-PET, SR & Cancer: $\downarrow$ metabolism \\
\hline Tashiro et al. ${ }^{45}$ & Various & $2 \mathrm{PC}, 7 \mathrm{C}+, 12 \mathrm{C}-, 10 \mathrm{H}$ & Cross-section & FDG-PET, SR & $\begin{array}{l}\text { Cancer: } \downarrow \text { metabolism; metabolism } \\
\text { correlated with depression } \\
\text { C+: } \downarrow \text { posterior metabolism }\end{array}$ \\
\hline Tashiro et al. ${ }^{42}$ & Various & $4 \mathrm{PC}, 3 \mathrm{C}-, 1 \mathrm{C}+$ & Cross-section & FDG-PET, NKA, SR & $\begin{array}{l}\text { Cancer: Metabolism, NKA, and } \\
\text { anxiety correlated }\end{array}$ \\
\hline Tashiro et al. ${ }^{43}$ & Various & $11 \mathrm{C}-, 5 \mathrm{C}+$ & Cross-section & FDG-PET, SR & $\begin{array}{l}\text { Cancer: Metabolism correlated with } \\
\text { social desirability }\end{array}$ \\
\hline Kumano et al. ${ }^{41}$ & Various & $6 \mathrm{C}+, 13 \mathrm{C}-$ & Longitudinal & FDG-PET, SR & $\begin{array}{l}\text { Cancer: BL metabolism associated } \\
\text { with depression change over time }\end{array}$ \\
\hline Golan et al. ${ }^{47}$ & lung & $18 \mathrm{PC}, 8 \mathrm{CS}, 11 \mathrm{~L}$ & PC cross-section & FDG-PET & PC: $\uparrow$ metabolism \\
\hline Benveniste et al..$^{48}$ & lung & $17 \mathrm{PC}, 15 \mathrm{H}$ & PC cross-section & 1H-MRS & PC: $\downarrow$ Neural markers \\
\hline
\end{tabular}

$\mathrm{PC}=$ cancer patients who have not yet received chemotherapy, $\mathrm{C}+=$ cancer patients treated with chemotherapy, $\mathrm{C}-=\mathrm{cancer}$ patients not treated with chemotherapy, $\mathrm{H}=$ healthy controls, $\mathrm{CS}=$ cancer survivors, $\mathrm{L}=$ individuals with benign lesions, FDG-PET=[F-18] Fluorodeoxyglucose positron emission tomography, $\mathrm{SR}=$ self-reported cognitive/psychological measures, $\mathrm{NKA}=$ natural killer cell activity, $\downarrow$ decrease, $\hat{\ell}$ increase, $\mathrm{BL}=$ baseline, Cancer=individuals with cancer, regardless of treatment status or time 